ORIGINAL RESEARCH

\title{
Antibody Response to SARS-CoV-2 in HIV Patients Co-Infected with COVID-19
}

\author{
Rumpa Saha ${ }^{*}$, Alpana Raizada ${ }^{2}$ Pooja Dewan ${ }^{3}$, Kirti Nirmal', Vikas Saini $^{5}$, Amir \\ Maroof Khan ${ }^{6}$, Narender Singh Mogha ${ }^{7}$, Shweta Jain ${ }^{8}$, Sunil Gomber ${ }^{9}$ and Narender \\ Pal Singh ${ }^{10}$
}

${ }^{1}$ Professor, Department of Microbiology, University College of Medical Sciences and Guru Tag Bahadur Hospital, Dilshad Garden, Delhi, India

${ }^{2}$ Professor, Department of Medicine, University College of Medical Sciences and Guru Tag Bahadur Hospital,Dilshad Garden, Delhi, India

${ }^{3}$ Professor, Department of Pediatrics, University College of Medical Sciences and Guru Tag Bahadur Hospital,Dilshad Garden, Delhi, India

${ }^{4}$ Assistant Professor, Department of Microbiology, University College of Medical Sciences and Guru Tag Bahadur Hospital, Dilshad Garden, Delhi, India

${ }_{5}^{5}$ Senior Resident, Department of Microbiology, University College of Medical Sciences and Guru Tag Bahadur Hospital, Dilshad Garden, Delhi, India

${ }^{6}$ Professor, Department of Preventive and Social Medicine, University College of Medical Sciences and Guru Tag Bahadur Hospital, Dilshad Garden, Delhi, India

${ }^{7}$ Senior Technical Assistant, University College of Medical Science \& Guru Teg Bahadur Hospital, Delhi, India

${ }^{8}$ Data Manager, ART Clinic, GTB Hospital, Delhi, India

${ }^{9}$ Director Professor, Department of Pediatrics, University College of Medical Sciences and Guru Tag Bahadur Hospital, Dilshad Garden, Delhi, India

${ }^{10}$ Director Professor and Head, Department of Microbiology, University College of Medical Sciences and Guru Tag Bahadur Hospital, Dilshad Garden, Delhi, India

*Corresponding author: Dr. Rumpa Saha, Professor, Department of Microbiology, University College of Medical Sciences and Guru Tag Bahadur Hospital, Dilshad Garden, Delhi 110095, India, Tel: 9212116906

\begin{abstract}
Introduction: As the spike protein of the SARS-CoV-2 envelope has been shown to be highly immunogenic and is the main target for neutralizing antibodies, the present pilot study aimed to evaluate the $\lg G$ antibody response to SARS-CoV-2 spike protein in HIV seropositive patients coinfected with COVID 19.

Material and methods: This cohort study was carried out in Delhi with HIV seropositive patients infected with COVID -19 whose 6 consecutive blood samples were collected after a gap of every 15 days starting at day 20 post Covid-19 positivity and tested for SARS-CoV-2 anti spike protein IgG antibody by ELISA.
\end{abstract}

Result: Of the 30 patients who were enrolled in this study, in $23.33 \%$ specific SARS-CoV-2 spike-binding IgG antibody were not detected in any of their samples. Of the $76.67 \%$ patients who had developed COVID-19 IgG antibody, 70\% were found to seroconvert at 3 weeks and stability of antibody remained at an average of 65 days post-infection in these patients.

Conclusion: The sero-conversion and stability of SARSCoV-2 anti spike protein IgG antibody in HIV seropositive individuals, who developed COVID-19 infections, are somewhat similar to general population with COVID-19 infections, starting at three weeks post-infection and persisting up to 2-4 months. Seroconversion may not be related to clinical severity of the disease. However $23.33 \%$ 
did not have detectable specific SARS-CoV-2 spike-binding IgG antibody in any of their samples till 3 months postinfection.

\section{Keywords}

Anti Spike protein antibody, COVID-19 antibody, HIV-CoV-2 co-infection, Stability, Seroconversion

\section{Introduction}

The infection with severe acute respiratory syndrome Coronavirus 2 (SARS-CoV-2) and the development of coronavirus disease 2019 (COVID-19) represents a major global health care challenge. Laboratory diagnosis of infected patients and the assessment of immunity against SARS-CoV-2, presents a major cornerstone in handling the pandemic. Laboratory testing is built on 2 different pillars: On one side, the detection of viral RNA, and on the other side measuring antibodies of various isotypes against SARS-CoV-2 components, reflecting the host immune response. Although antibodies develop quite early during the course of the disease, the serological response is not suitable for early detection of infected patients.

The spike protein (SP) of the SARS-CoV-2 envelope has been shown to be highly immunogenic and is the main target for neutralizing antibodies [1]. By day 14 after symptom onset, the serum of $95-100 \%$ of patients with COVID-19 contains IgG antibodies to the Spike Protein of the SARS-CoV-2 envelope, including antibodies to the receptor-binding domain (RBD) of the SP, which strongly correlate with antibodies that neutralize viral replication in cell cultures (i.e. neutralizing antibodies NtAb) [24]. However, studies have also shown some people who presented positivity in results from the molecular test did not have detectable levels of protective IgG antibody. Furthermore, neutralizing antibodies were low or not at all present even in hospitalized patients $[5,6]$. This situation raises questions about protective immunity and about the ability of patients to mount an antibody response.

Due to the lack of published academic work for coinfections of SARS CoV-2 in HIV seropositive patients (HIV-CoV-2) not much is known about the clinical and epidemiological outcomes in such patients. It is not clear whether this lack of published data is due to the lack of screening for the HIV-CoV-2, or whether the SARS CoV-2 is just not present frequently in HIV seropositive patients. During the current coronavirus pandemic, this lack of information is a concern in countries with high HIV cases, especially in Sub-Saharan Africa-where $70 \%$ of people living with HIV are found [7]. Knowledge about HIV reveals that the virus attacks and destroys the immune system and specific antibody responses are delayed or even fail to develop, which consequently results in the long course of this disease. Except for isolated case reports and very few case series literature fails to document studies focusing on immune response in patients living with HIV and is co-infected with COVID-19 [8-10].

With this background, the present pilot study aimed to evaluate the IgG antibody levels to SARS-CoV-2 spike protein in HIV seropositive patients co-infected with COVID-19.

The objective was to find out the IgG antibody response to SARS-CoV-2 SP in HIV seropositive patients co-infected with COVID 19 by an ELISA based kit and also evaluate the time of appearance and disappearance of this antibody in these patients. This study also correlate's SARS-CoV-2 antibody levels with CD4+ T-cell counts and severity of both HIV as well as COVID-19.

\section{Material and Methods}

This cohort study was carried out in the department of Microbiology and ART clinic of a tertiary tertiary care hospital in Delhi within a time frame of 4 months after approval by Institutional Ethical Committee (IEC). Informed written consent and assent (as applicable) were obtained from all participants/caregivers (for children).

HIV seropositive patients of all age groups, either sex, infected with COVID-19 as evidenced by a positive RT-PCR or Rapid Ag test for Covid-19 were included in the study. As this was a pilot study sample size could not be calculated.

Patients on immunomodulators or prolonged steroids were excluded from the study.

\section{Methodology}

6 consecutive $2 \mathrm{ml}$ blood samples were collected after a gap of every 15 days on day $20^{\text {th }}, 35^{\text {th }}, 50^{\text {th }}, 65^{\text {th }}$, $80^{\text {th }}, 95^{\text {th }}$ and $110^{\text {th }}$ days after Covid-19 positivity and serum was tested form anti SP IgG antibody to SARSCoV-2 using an ELISA based kit following manufacturer's instructions (ErbaLisa COVID-19 IgG ELISA Transasia BioMedicals Ltd, India, Sensitivity $99.12 \%$ and Specificity 99.33\%). The levels and the time course of SARS-CoV2-specific spike-binding IgG antibodies were monitored every 15 days as reflected by the antibody index. At the first visit after COVID-19 positivity, CD4+ count was also estimated. At any point of time when a patient turned SARS-CoV-2 Ab negative after initial positivity, no further blood samples was taken from that person.

Demographic profile and WHO clinical staging of HIV were obtained from records/telephonic interview. Laboratory parameters (maintained at the ART Clinic) like recent CD4 count and viral load of HIV were obtained from records.

Patients were categorized into mild, moderate and severe cases of Covid-19 illness as per Ministry of Health and Family Welfare (MoHFW) guidelines version 3, dated 13.06.20 [11]. 


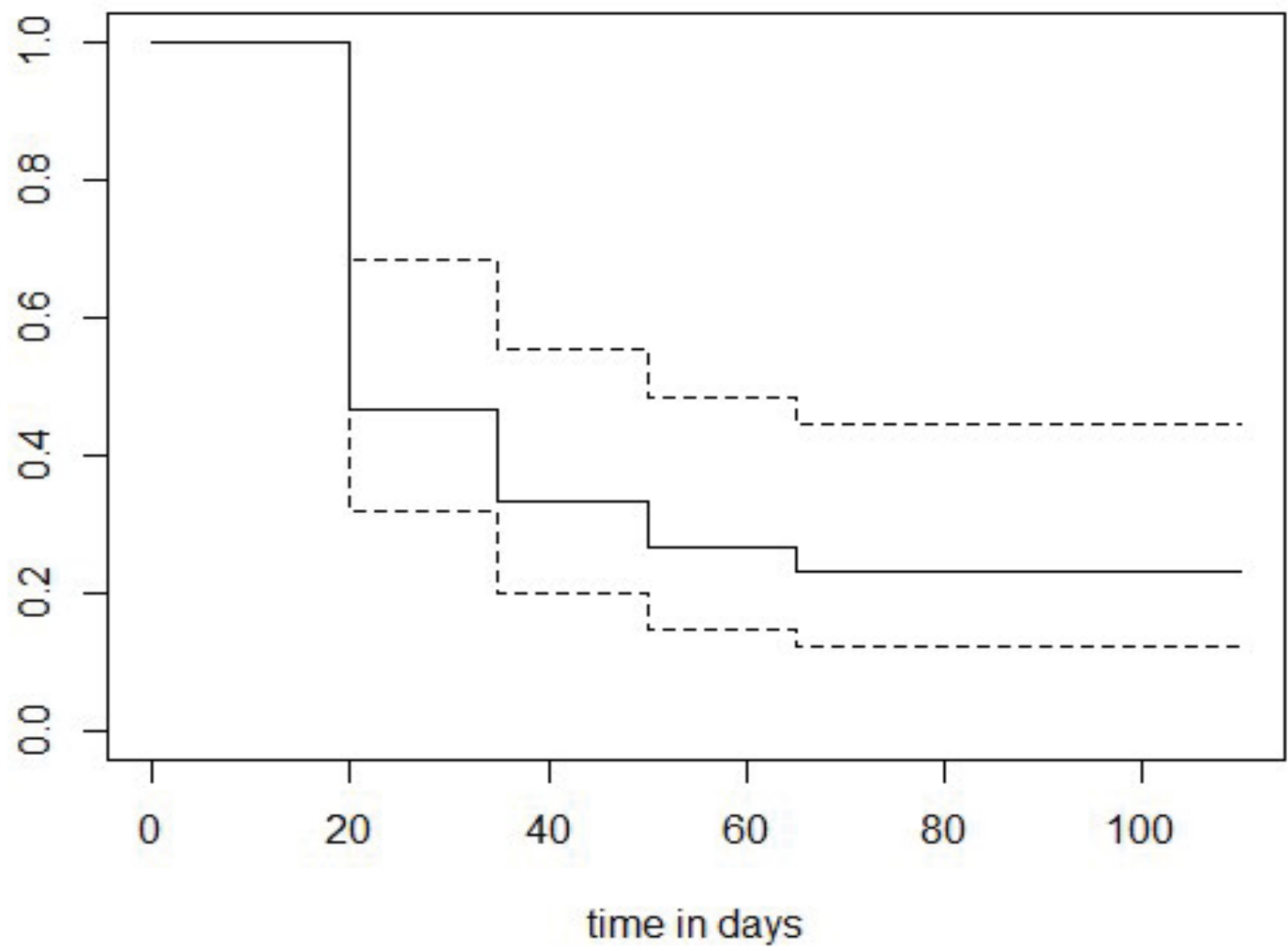

Figure 1: Kaplen Meier curve showing shows the probability of respondents not showing detectable antibody decreasing over time.

\section{Mild}

Patients with uncomplicated upper respiratory tract infection may have mild symptoms such as fever, cough, sore throat, nasal congestion, malaise, headache, without evidence of breathlessness or Hypoxia (normal saturation). Managed at Covid Care Centre (CCC/at home).

\section{Moderate}

Pneumonia with no signs of severe disease, with presence of dyspnea and or hypoxia, fever, cough, including $\mathrm{SpO}_{2}<94 \%$ on room air, respiratory rate $\geq 24$ / minute.

In case of child fast breathing (in breaths/min) : $<2$ months: $\geq 60$; 2-11 months: $\geq 50 ; 1-5$ years: $\geq 40$. Managed at Dedicated Covid Health Centre (DCHC).

\section{Severe}

Severe Pneumonia: Adolescent or adult: with clinical signs of Pneumonia plus one of the following; respiratory rate > 30 breaths/min, severe respiratory distress, $\mathrm{SpO}_{2}<90 \%$ on room air. Child with cough or difficulty in breathing, plus at least one of the following: central cyanosis or $\mathrm{SpO}_{2}<90 \%$; severe respiratory distress (e.g. grunting, chest in-drawing); signs of pneumonia with any of the following danger signs: Inability to breastfeed or drink, lethargy or unconsciousness, or convulsions. Other signs of pneumonia may be present: chest in drawing, fast breathing (in breaths/min): $<2$ months $\geq$ $60 ; 2-11$ months $\geq 50 ; 1-5$ years $\geq 40$. Managed at DCHC.
All samples were obtained using universal precautions and use of PPE (as necessary). The waste samples were disposed off as per Biomedical Waste Management rules after completion of study.

\section{Results}

Initially 32 patients had been recruited in the present study as per our inclusion criteria. However due to death of one patient and refusal to give further sample by another patient, finally 30 patients were enrolled in this study.

Male patients (64\%) outnumbered the females (28\%) and transgenders (8\%).

Most of these patients were in the age group of 4050 years (43\%). The median age of these patients were 35 years (ranging from 2 to 50 years). (The Interquartile range at $25^{\text {th }}$ and $75^{\text {th }}$ percentile was: 1,2 ).

\section{Development of COVID-19 IgG antibody in HIV- CoV-2 patients}

Out of 30 HIV-CoV-2 infected patients, 7 patients (23.33\%) did not have detectable specific SARS-CoV-2 spike-binding IgG antibody in any of their samples till 3 months post-infection. Rest 23 patients (76.67\%) developed antibody at different time period postinfection (Figure 1).

Of the 23 patients who had developed COVID-19 IgG antibody, 16 patients (69.67\%) were found to possess IgG antibody on the $20^{\text {th }}$ post-infection day, 4 patients 


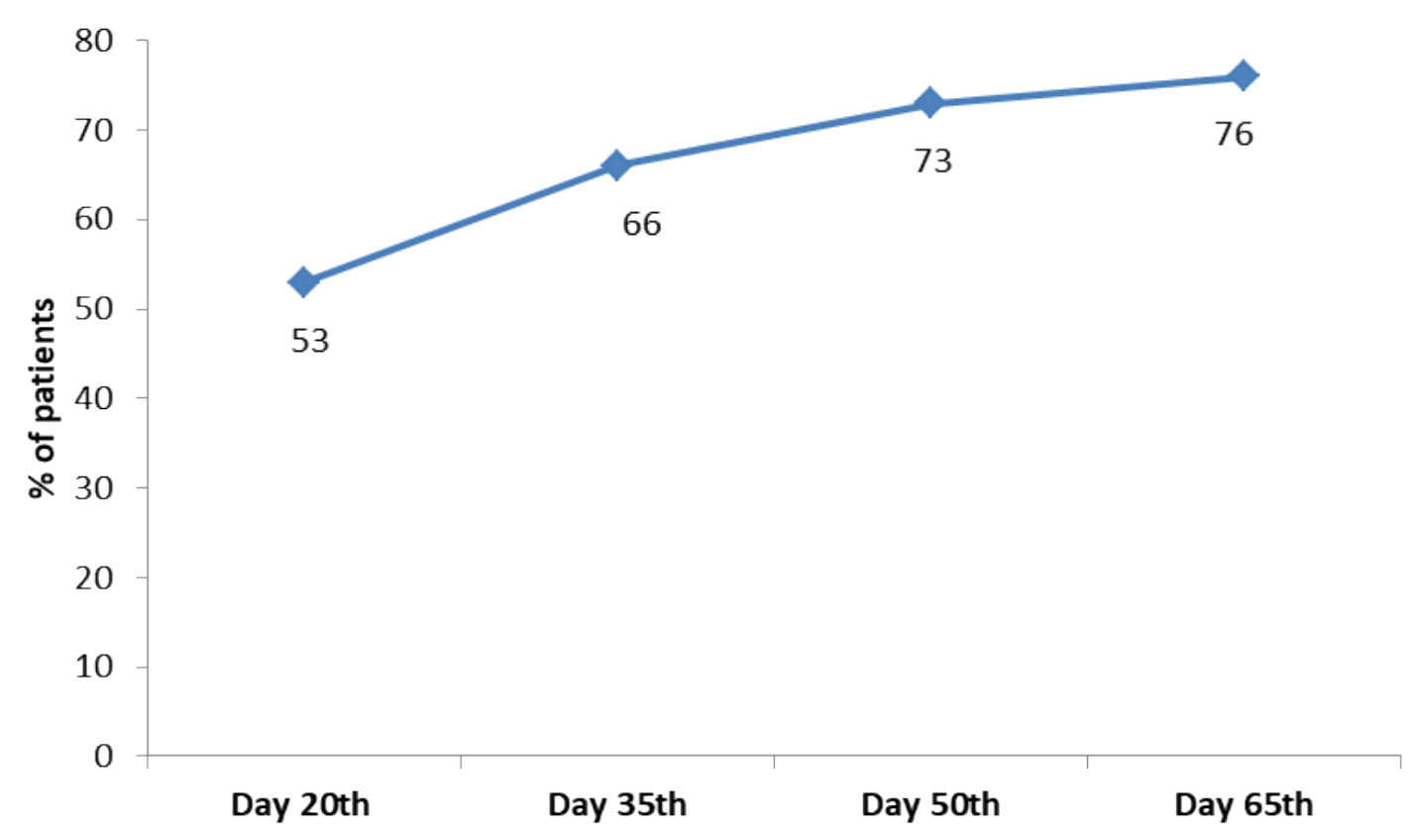

COVID-19 IgG antibody (days)

Figure 2: COVID-19 IgG antibody positivity in HIV-CoV-2 patients.

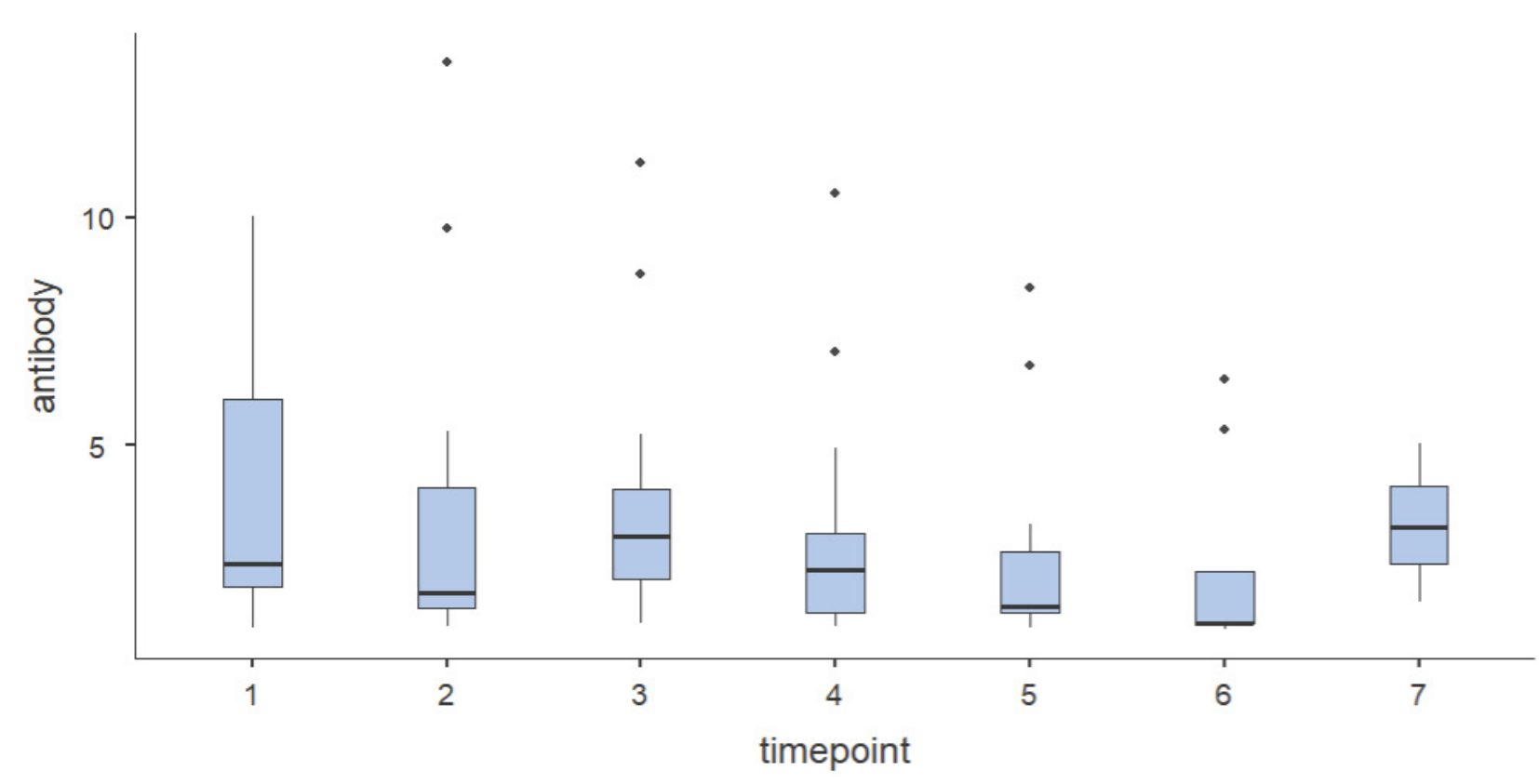

Figure 3: Box plot description of anti-SARS-CoV-2 spike protein IgG antibody index at various time points (day $20^{\text {th }}, 35^{\text {th }}$, $50^{\text {th }}, 65^{\text {th }}, 80^{\text {th }}, 95^{\text {th }} \& 110^{\text {th }}$ ) among those HIV-CoV-2 patients in which detectable antibody were seen.

Time points $1=20^{\text {th }}$ day, $2=35^{\text {th }}$ day, $3=50^{\text {th }}$ day, $4=65^{\text {th }}$ day, $5=80^{\text {th }}$ day, $6=95^{\text {th }}$ and $7=110^{\text {th }}$ day of COVID antibody sample.

$(17 \%)$ on the $35^{\text {th }}$ day, 2 patients $(8.6 \%)$ on the $50^{\text {th }}$ day and 1 patient on $65^{\text {th }}$ day post-infection (Figure 2).

\section{Stability of COVID-19 IgG antibody in HIV-CoV-2 patients}

Approximately $70 \%$ (16 out of 23 patients) of the participants had antibody stability till $65^{\text {th }}$ day postinfection. Out of these 23 patients who had sero- converted, 13\% (3 patients) showed persistence of COVID antibody beyond three and half months although their antibody index decreased in successive samples. Further samples of these 3 patients for detecting antibody were beyond the scope of this study. Six patients $(26 \%)$ had antibody stability lasting for up to 3 months. The stability of COVID-19 IgG antibody positivity in HIV-CoV-2 patients is predicted in Figure 3. 


\section{Characteristic of HIV seropositivity in SARS-CoV-2 patients}

All HIV-CoV-2 patients were on anti-retroviral treatment (ART) except one patient. This patient although develop low antibody index at 3 weeks postinfection, it did not last beyond this time.

CD4 counts of all patients were $\geq 200$ cells $/ \mathrm{mm}^{3}$ except one patient. This patient with $\mathrm{CD}_{4}$ count of 34 cells $/ \mathrm{mm}^{3}$ did not develop antibody response at all. The median CD4 count of these patients was 300 cells $/ \mathrm{mm}^{3}$ (ranging from less than 50 to more than 500 cells $/ \mathrm{mm}^{3}$ ). The Interquartile range at $25^{\text {th }}$ and $75^{\text {th }}$ percentile was 1.25 and 3.

Two patients (6.7\%) had high viral load (> 1000 copies per $\mathrm{ml}$ ) while 28 patients $(93.4 \%$ ) did not reach the target level for detection of HIV viral load. These patients with high viral load also had no detectable antibody response till 3 months post-infection.

All patients were in clinical staging AIDS category I, except one patient who was in category III AIDS. This patient also had no detectable antibody response till 3 months post-infection.

$93 \%$ of patients were in mild clinical category of COVID-19 and two patients $(6.6 \%)$ had moderate disease. These two patients were hospitalized for oxygen support only and were discharged after 10 days. These patients did not need intensive care admission. These two patients who were hospitalized (COVID-19 moderate category) had detectable antibody response which lasted beyond 110 days post-infection.
The other patient whose detectable antibody response was beyond 110 days had multiple mild symptoms like fever $\left(99-100{ }^{\circ} \mathrm{F}\right)$, dry cough, anosmia, dysgeusia and also 3 co-morbidities.

Out of 30 patients, 28 (93.3\%) had associated comorbidities, while two patients $(6.6 \%)$ did not have any co-morbidity. The most common co-morbidity was hypertension (20\%). More than one co-morbidity was seen in 4 patients (14\%). Two of these patients had more than 2 co-morbidities and had antibody stability for more than $110^{\text {th }}$ day. Other two patients had more than 3 co-morbidities but antibody stability was till $95^{\text {th }}$ day in one and more than $110^{\text {th }}$ day in the other Figure 4.

\section{Discussion}

In present study, $76.67 \%$ ( 23 out of 30 ) of patients had showed a positive antibody response to spike (S) protein of SARS-CoV-2 at different time periods post-infection starting with 3 weeks after infection. Seroconversion to SARS-CoV-2 was noted in $70 \%$ (16 out of 23 ) of HIV seropositive individuals in the present study at a median of 3 weeks post-infection. Rest of the participants seroconverted at day $35^{\text {th }}(17 \%)$, day $50^{\text {th }}(9 \%)$ and day $65^{\text {th }}$ (4\%). Present study corroborates with finding by Shinay, et al. from Japan where seroconversion was seen in 30 days post symptoms onset in HIV patients with SARS-CoV-2 [12]. In studies with non HIV seropositive COVID-19 infected individuals seroconversion has been documented at a median of 10-14 days [2]. Although seroconversion could have appeared earlier in present study but the authors did not look for antibody before

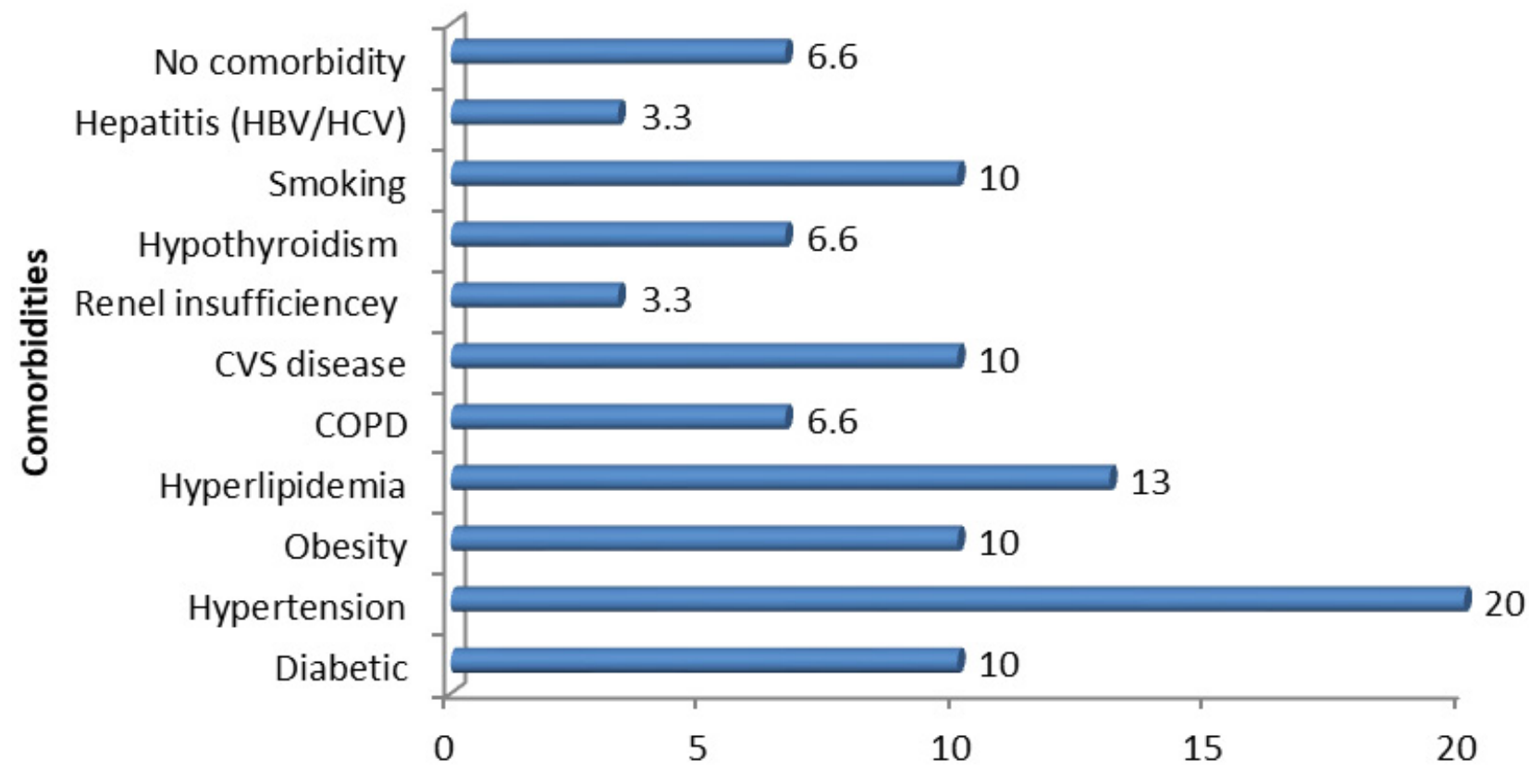

$\%$ of patients

Figure 4: Distribution of various Co-morbidities of SARS-CoV-2 patients. 
20 days post-infection. Similar studies from Spain, Germany and China showed $75 \%, 95 \%$ and $100 \%$ rate seroconversion at a median of 11 days, 21 days and 19 days respectively [13-15]. In another study from Philippines, patients with diagnosis of solid malignancies showed seroconversion in $94 \%$ cases [16]. In the same study significantly lower seroconversion was observed in patients with hematological malignancy $(82 \%)$, stem cell transplant recipients $(60 \%)$ and in patients who received anti-CD-20 antibody therapy (59\%), although $100 \%$ seroconversion was seen in patients who received monoclonal antibody [16]. These data show differential rates of seroconversion in specific patient groups as compared to general population and can be important for clinical monitoring and vaccination strategies. Seroconversion is important in patients who are immunodeficient as in HIV or those who receive immunosuppressive therapy as mounting humoral immunity to COVID-19 is crucial not only in recovering from this COVID-19 but also to establish and maintain herd immunity through effective vaccination strategy.

$23 \%$ of our patients did not mount a detectable IgG response to COVID-19 spike protein, although all of these (except one) had $\mathrm{CD}_{4}$ count $>200$ cells $/ \mathrm{mm}^{3}$. Study from Wuhan, China in HIV individuals showed no antibody response though their patients had $C_{4}$ count of $<50$ cells/ $\mu \mathrm{L}[17,18]$. Although Zhao, et al. suggests that low CD4+ T-cell count might partly explain the incomplete viral clearance and delayed humoral responses towards SARS, nevertheless this was not the case in the present study [19]. As number of CD4+ cells, is probably not a direct cause, so other causes of innate immune response like the activity of macrophages/ dendritic cells and $B$ cells may have a role and further research in such field will help at arriving to a plausible conclusion.

Approximately $7 \%$ of our patients who did not seroconvert had high viral load for HIV (> 1000 copies/ $\mathrm{ml}$ ). Another $3 \%$ of these who did not seroconvert was in category III of clinical staging of AIDS. Probability of destruction of the immune response by the two viruses together also remains a possibility. More research into this aspect with large cohorts are needed to characterize this further. Studies in HIV-1-infected children and adults have shown that blood resting memory cells are reduced in number during HIV-1 infection and that their decline correlates with reduction of antibody $(A b)$ titers against childhood vaccinations $[20,21]$. This fact can influence activation of $B$ cell and subsequent generation of specific SARS-CoV-2 spike-binding IgG antibody. Whether vaccination strategy for these patients will be effective in such situation needs further exploration.

In the present study time to seroconversion was not related to clinical severity of COVID-19 disease ( $60 \%$ of the mild cases in present study sero-converted by 20 days post-infection) as is evident from documented studies $[15,22-25]$, More studies are required to establish that clinical severity is associated with significantly earlier seroconversion.

Present study documents decrease in antibody levels subsequently in successive samples in all patients as evidenced by the antibody index, until it ultimately became undetectable. Persistence of detectable antibodies beyond three and half months (110 days) was not seen in most (86.96\%) of our patients. Approximately $70 \%$ (16 out of 23 patients) of the participants had antibody stability till day $65^{\text {th }}$ post-infection and only $13 \%$ patients had persistence of antibody till (110 days), similar to study from Canada in general population with COVID-19 infection, where persistence of anti-spike IgG antibody was up to 105th day post symptom onset [2]. Study from Japan showed persistence of SARS-CoV-2 antibody in HIV patients for upto 120 days post symptoms onset similar to studies from North America in non HIV individuals [12,28]. Data from available literature documents that anti-SARSCoV-2 spike protein IgG antibody level remained fairly stable, at $75-115^{\text {th }}$ day post symptoms onset [26-30]. Of the $13 \%$ whose antibody persisted beyond 110 days, two patients needed hospitalization due to moderate clinical severity of COVID-19 disease. But whether clinical severity of COVID is associated with longer persistence of antibody also needs further supportive studies for documentation in literature.

The median age of participant in the present study was 35 years and with a short course and complete recovery. Study by Scott, et al. documents similar course and recovery in their short series of HIV patients with COVID-19 [9]. A similar case series by Georg, et al. also report similar experience among symptomatic COVID-19 patients living with HIV on ART [10]. In contrast, studies from China reports long disease course and from New York reports severe disease (89\%) and mortality (78\%) $[15,31]$. Recent evidence suggests that in those who have low $\mathrm{CD}_{4}+\mathrm{T}$-cells lymphocytes, several clinical features including older age, elevated inflammatory markers and chest X-ray abnormalities are predictive factors of severe COVID-19 and death [19,34,35]. HIV related lymphopenia can delay the clearance of virus and promote progression of the disease. However, further large observational studies are needed to verify these facts.

In present study majority of patients were males ( $M$ : F: Transgender $=16: 7: 2$ ) similar to study from Italy and China in HIV-CoV-2 population [34,35].

93.3\% patients in present study had associated comorbidities of which the most common of which were hypertensions (20\%) and hyperlipidemia (13.3\%) similar to study in HIV patients from Iran [36]. The impression that co-morbidities may be an important factor for mortality in SARS-CoV-2 infection needs more studies to 
be a established in HIV-CoV-2 co-infected cases to arrive at an useful conclusion for better management of such patients.

\section{Conclusion}

HIV-CoV-2 coinfected patient usually seroconvert in approximately similar time period to non HIV COVID-19 infected individuals. This ability to develop natural immunity against the SARS-CoV-2 in HIV seropositive individuals bodes well for a good response to COVID-19 vaccines although literature denotes decline in resting memory cells may decline Ab production. Seroconversion may not be related to clinical severity of the disease. The stability of antispike antibody in such individuals is also somewhat similar to general population with COVID-19 individuals persisting upto 3-4 months. The most common co-morbidities were hypertension and hyperlipidemia, but whether co-morbidities increase mortality is AIDS patients is still to be established.

\section{Limitation of the Study}

This was a pilot study with a small sample size. Thus, further large observational and cohort studies are needed to establish these data. This will help in understanding the clinical course and progression to severe disease in patients with HIV and will help in better management and prevention of COVID-19 and HIV patients.

Moreover, the possibility of using other biological parameters like CCR7, CCL19 and CCL21, to measure the time of emergence of specific SARS-CoV-2 spikebinding IgG antibody in such HIV patients has not been explored as it was not within the scope of our study. These parameters probably have a role in increased permissiveness of resting memory CD4+ T-cells to HIV infection and post integration latency [37]. This area may be further looked into in subsequent studies for not only for time of emergence of $A b$ but also for establishment of probable role in Covid vaccination strategy in these HIV patients.

\section{Sources of Support}

Nil.

\section{Acknowledgement}

Nil.

\section{Registration Number of Clinical Trial}

Not applicable.

\section{References}

1. Ou X, Liu Y, Lei X, Pei Li, Dan Mi, et al. (2020) Characterization of spike glycoprotein of SARS-CoV-2 on virus entry and its immune cross-reactivity with SARS-CoV. Nat Commun 11: 1620.

2. Zhao J, Yuan Q, Wang H, Liu W, Liao X, et al. (2020) Antibody responses to SARS-CoV-2 in patients of novel coronavirus disease 2019. Clin Infect Dis 10: 213-224.
3. To KK, Tsang OT, Leung WS, Tam AR, Wu TC, et al. (2020) Temporal profiles of viral load in posterior oropharyngeal saliva samples and serum antibody responses during infection by SARS-CoV-2: An observational cohort study. Lancet Infect Dis 20: 565-574.

4. Wölfel R, Corman VM, Guggemos W, Seilmaier M, Zange S, et al. (2020) Virological assessment of hospitalized patients with COVID-2019. Nature 581: 465-469.

5. Huang AT, Carreras BG, Hitchings MDT, B Yang, L Katzelnick, et al. (2020) A systematic review of antibody mediated immunity to coronaviruses: antibody kinetics, correlates of protection, and association of antibody responses with severity of disease. Infectious Diseases (except HIVIAIDS).

6. Wu F, Wang A, M Liu, Q Wang, J Chen, et al. (2020) Neutralizing antibody responses to SARS-CoV-2 in a COVID-19 recovered patient cohort and their implications. Infectious Diseases (except HIVIAIDS) 23: 2314-2320.

7. Lee HK, Lee BH, Seok SH, Beak WM, Lee YH, et al. (2010) Production of specific antibodies against SARS-coronavirus nucleocapsid protein without cross reactivity with human coronavirus 229E and OC43. J Vet Sci 11: 165-167.

8. WHO. Coronavirus (Online).

9. Scott BDO, Michelle KMD, Eric SMD (2020) Four cases: Human immunodeficiency virus and novel coronavirus 2019 Co-infection in patients from Long Island, New York.

10. Härter G, Spinner CD, Roider, J, Bickel, M, Krznaric, I, et al. (2020) COVID-19 in people living with human immunodeficiency virus: A case series of 33 patients. Infection 48: 681-686.

11. (2020) Clinical Management Protocol: COVID19.

12. Yamamoto $S$, Saito $M$, Nagai $E$, Toriuchi $K$, Nagai $H$, Yotsuyanagi $\mathrm{H}$, et al. (2020) Antibody response to SARSCoV-2 in people living with HIV. J Microbiol Immunol Infect 54: 144-146.

13. Masiá M, Telenti G, Fernández M, García JA, Agulló V, et al. (2021) SARS-CoV-2 Seroconversion and Viral Clearance in Patients Hospitalized With COVID-19: Viral Load Predicts Antibody Response. Open Forum Infect Dis 8: ofab005.

14. Gluck V, Perez-Elias MJ, Quereda C, Moreno A, Vivancos $M$, et al. (2020) Description of COVID-19 in HIV-infected individuals: A single-centre, prospective cohort. Lancet HIV 7: e554-e564.

15. Long QX, Liu BZ, Deng HJ, Wu GC, Deng K, et al. (2020) Antibody responses to SARS-CoV-2 in patients with COVID-19. Nature Medicine 26: 845-848.

16. Thakkar A, Pradhan K, Jindal S, Cui Z, Rockwell B, et al. (2021) Patterns of seroconversion for SARS-CoV 2-IgG in patients with malignant disease and association with anticancer therapy. Nat Cancer 2: 392-399.

17. Ruan, L, Zhang Y, Luo Y, Yu X, Zeng Y, et al. (2020) Clinical features and outcomes of four HIV patients with COVID-19 in Wuhan, China. J Med Virol 93: 133-136.

18. Wang M, Luo L, Bu H, Xia H (2020) Case Report: One Case of Coronavirus Disease 2019(COVID-19) in Patient Co-infected by HIV With a Low CD4+ T Cell Count. Int $\mathrm{J}$ of Infect Dis 96: 148-150.

19. Zhao J, Liao X, Wang H, Wei L, Xing M, et al. (2020) Early virus clearance and delayed antibody response in a case of COVID-19 with a history of co-infection with HIV-1 and HCV. Clin Infect Dis 71: 2233-2235. 
20. Cagigi A, Nilsson A, Pensieroso S, Chiodi F (2010) Dysfunctional B-cell responses during HIV-1 infection: Implication for influenza vaccination and highly active antiretroviral therapy. Lancet Infect Dis 10: 499-503.

21. Amu S, Ruffin N, Rethi B, Chiodi F (2013) Impairment of B-cell functions during HIV-1 infection. AIDS 27: 23232334.

22. Marklund E, Leach S, Axelsson H, Nystro"MK, Norder $H$, et al. (2020) Serum-lgG responses to SARS-CoV-2 after mild and severe COVID-19 infection and analysis of IgG nonresponders. PLoS ONE 15: e0241104.

23. Cervia C, Nilsson J, Zurbuchen Y, Valaperti A, Schreiner $J$, et al. (2020) Systemic and mucosal antibody secretion specific to SARS-CoV-2 during mild versus severe COVID-19. bioRxiv 5: 108308.

24. Yu HQ, Sun BQ, Fang ZF, Zhao JC, Liu XY, et al. (2020) Distinct features of SARS-CoV-2-specific IgA response in COVID-19 patients. Eur Respir J 56: 2001526.

25. Ma H, Zeng $W$, He $H$, Zhao D, Jiang D, et al. (2020) Serum IgA, IgM, and IgG responses in COVID-19. Cell Mol Immunol 17: 773-775.

26. Iyera AS, Jones FK, Nodushani N, Kelly M, Becker M, et al. (2020) Dynamics and significance of the antibody response to SARS-CoV-2 infection. MedRxiv 45: 345-368.

27. Wajnberg A, Amanat F, Firpo A, Altman RD, Bailey MJ, et al. (2020) SARS-CoV-2 infection induces robust, neutralizing antibody responses that are stable for at least three months. MedRxiv 34: 2123-2134.

28. Pradenas E, Trinité B, Urrea V, Marfil S, Ávila-Nieto C, et al. (2021) Stable neutralizing antibody levels 6 months after mild and severe COVID-19 episodes. Med (N Y) 2: 313320.e4.
29. Dan JM, Mateus J, Kato Y, Hastie KM, Yu ED, et al. (2021) Immunological memory to SARS-CoV-2 assessed for up to 8 months after infection. Science 371: eabf4063.

30. Yao L, Wang GL, Shen Y, Wang ZY, Zhan BD, et al. (2021) Persistence of Antibody and Cellular Immune Responses in COVID-19 patients over Nine Months after Infection. J Infect Dis 224: 586-594.

31. Suwanwongse K, Shabarek N (2020) Clinical features and outcome of HIV/SARS-CoV-2 co-infected patients in the Bronx, New York City. J Med Virol 92: 2387-2389.

32. Wu C, Chen X, Cai Y, Xia C, Zhou X, et al. (2019) Risk Factors Associated With Acute Respiratory Distress Syndrome and Death in Patients With Coronavirus Disease 2019 Pneumonia in Wuhan, China. JAMA Intern Med 180: 934-943.

33. Fu L, Wang B, Yuan T, Chen X, Cai Y, et al. (2020) Clinical characteristics of Coronavirus disease 2019 (COVID-19) in China: A systematic review and meta-analysis. J Infect 80 : 656-665.

34. Livingston E, Bucher K (2020) Coronavirus disease 2019 (COVID-19) in Italy. JAMA 323: 1335.

35. Chen N, Zhou M, Dong X, Qu J, Gong F, et al. (2020) Epidemiological and clinical characteristics of 99 cases of 2019 novel Coronavirus pneumonia in Wuhan, China: A descriptive study. Lancet 395: 507-513.

36. Karamouzian M, Nasirian M, Hoseini SG, Mirzazadeh A (2020) HIV and other sexually transmitted infections among female sex workers in Iran: A systematic review and metaanalysis. Arch Sex Behav 49: 1923-1937.

37. Saleh S, Solomon A, Wightman F, Xhilaga M, Cameron PU, et al. (2007) CCR7 ligands CCL19 and CCL21 increase permissiveness of resting memory CD4_T cells to HIV-1 infection: A novel model of HIV-1 latency. Blood 110: 41614164. 